Preprint of the: Fabró, F., J. Montanyà, N. Pineda, O. Argemí, O. A. van der Velde, D. Romero, and S. Soula (2016), Analysis of energetic radiation associated with thunderstorms in the Ebro delta region in Spain, J. Geophys. Res. Atmos., 121, doi:10.1002/2015JD024573.

\title{
Analysis of energetic radiation associated with thunderstorms in the Ebro delta region in Spain
}

Ferran Fabró $^{1}$, Joan Montanyà ${ }^{1}$, Nicolau Pineda ${ }^{2}$, Oriol Argemí ${ }^{2}$, Oscar A.

van der Velde ${ }^{1}$, David Romero ${ }^{1}$, Serge Soula ${ }^{3}$

Corresponding author: F. Fabró, Department of Electrical Enginnering, Polytechnical University of Catalonia, Building TR1, Terrassa 08222, Barcelona, Spain. (ferran.fabro@upc.edu)

\footnotetext{
${ }^{1}$ Electrical Engineering Department,

Universitat Politècnica de Catalunya,

Barcelona, Spain.

${ }^{2}$ Meteorological Service of Catalonia,

Barcelona, Spain

${ }^{3}$ Laboratoire dAérologie, Université de

Toulouse, CNRS, Toulouse, France
} 


\section{Key Points.}

- Background radiation during thunderstorms

- Radiation emitted by radon-ion daughters

- Experimental evidences of possible TGE detected

3 Abstract. The analysis of high-energy background radiation (0.1-2MeV)

4 enhancements during eight winter thunderstorms and five summer storms

${ }_{5}$ in the Ebro delta region in the northeast of Spain is presented. For the first

6 time, high-energy radiation counts, precipitation, radar reflectivity and very

7 high frequency lightning detections to infer charge regions altitude have been

$s$ analysed in order to find out what produces the measured background ra-

9 diation increments associated with storms. The good agreement between radar

10 reflectivity and precipitation with increases in background radiation counts

11 coupled with the spectrum analysis comparing rain/no rain periods suggests

${ }_{12}$ that radon-ion daughters play a major role in the radiation increments re-

${ }_{13}$ ported. No evidence has been found supporting that measured background

${ }_{14}$ radiation enhancements can be produced by storm electric fields. Finally, a

15 single case of a high energy radiation increase was prior to a cloud-to-ground

${ }_{16}$ lightning stroke which reinforces the theory of a lower positive charge layer

${ }_{17}$ to exist is important for the production of Terrestrial Ground Enhancements

18 (TGEs). 


\section{Introduction}

Since Wilson [1925] predicted that very energetic electrons within thunderstorm electric fields would be accelerated up to $\mathrm{GeV}$ energies, different experiments have shown

${ }_{21}$ that bursts of high-energy radiation occur inside thunderstorms. It is thought that those

22 bursts are produced by the mechanism known as Relativistic Runaway Electron Avalanche

${ }_{23}$ (RREA), first introduced by Gurevich et al. [1992]. Referring to this mechanism, if the

${ }_{24}$ electrons (so called seed electrons) within an electric field are enough energetic to over-

${ }_{25}$ come the frictional force, they are accelerated up to relativistic energies. These relativistic

${ }_{26}$ electrons collide with air molecules producing new ones, leading to an avalanche of rela-

${ }_{27}$ tivistic electrons that produce bursts of high energy radiation by Bremsstrahlung effect.

${ }_{28}$ Two different theories are proposed to explain the origin of the seed electrons.

29

The first one suggests that the seed electrons would be produced in the very high electric

so fields in lightning leader tips [Dwyer, 2008, 2010; Carlson et al., 2009, 2010; Celestin and

${ }_{31}$ Pasko, 2011] by the process known as cold runaway [Gurevich, 1961; Dwyer et al., 2004].

32 This mechanism would explain the bursts lasting milliseconds or less, generally observed

${ }_{33}$ in association with lightning that can be divided in two categories. The first one are the

${ }_{34}$ Terrestrial Gamma ray Flashes (TGFs) discovered by Fishman et al. [1994], detected in

35 the upper atmosphere by instrumented satellites. Source altitude of TGFs is between 15

${ }_{36}$ and 21 km [Dwyer and Smith, 2005; Carlson et al., 2007; Østgaard et al., 2008; Hazelton

${ }_{37}$ et al., 2009; Gjesteland et al., 2010] and they are thought to be produced by RREA of

${ }_{38}$ runaway electrons produced in the fronts of positive intra-cloud (IC) lightning leaders

39 [Williams et al., 2006; Lu et al., 2010; Shao et al., 2010]. The second one are the X rays 
40 detected at ground first observed by Moore et al. [2001]. In this case, the radiation has

${ }_{41}$ been detected in different situations like associated with leader steps of rocket triggered

${ }_{42}$ lightning [Dwyer et al., 2003], in multiple occasions associated with downward negative

43 stepped leaders [Dwyer, 2005b; Howard et al., 2008; Saleh et al., 2009; Schaal et al.,

44 2013; Mallick et al., 2012; Montanyà et al., 2014] and only in one case associated with

${ }_{45}$ upward leaders of both polarities [Yoshida et al., 2008]. It is thought that those $\mathrm{X}$ rays

${ }_{46}$ are produced by Bremsstrahlung effect of runaway electrons produced by cold runaway

${ }_{47}$ which is the same candidate process to explain X-rays in laboratory sparks [Dwyer, 2005a;

${ }_{48}$ Dwyer et al., 2008; Nguyen et al., 2008; March et al., 2009; March and Montanyà, 2010;

49 Shao et al., 2011; Kochkin et al., 2012]. These very short-lasting events observed on

50 ground detectors should be produced by negative IC lightning by the same mechanism as ${ }_{51}$ TGFs.

${ }_{52}$ The second theory proposes that the seed electrons are secondary cosmic rays [Dwyer ${ }_{53}$ et al., 2003, 2008, 2012]. This theory is a very well proven phenomenon by the observation ${ }_{54}$ of the long TGEs, which are high energetic fluxes with durations of several seconds to ${ }_{55}$ several minutes and energies up to $10 \mathrm{MeV}$ that seem to be modulated by the electric ${ }_{56}$ field of thunderstorms [Torii et al., 2009; Chilingarian et al., 2012]. Those events are often ${ }_{57}$ formed by $\gamma$ radiation and energetic particles such as electrons and neutrons [Chilingar${ }_{58}$ ian et al., 2010]. Even if long TGEs have been observed in different situations, they have ${ }_{59}$ always been associated with thunderstorms. TGEs have been detected at altitudes above ${ }_{60} 2500$ m [Torii et al., 2009; Tsuchiya et al., 2009; Chilingarian et al., 2011, 2012; Chilingar${ }_{61}$ ian and Mkrtchyan, 2012; Gurevich et al., 2013], at sea level associated only with winter ${ }_{62}$ thunderstorms [Torii et al., 2008, 2011], by balloons [Parks et al., 1981] and airplanes 
${ }_{63}$ [Eack et al., 1996]. Simulations [Babich and Loiko, 2010] have shown that long TGEs are

${ }_{64}$ produced inside tropospheric thunderclouds by RREAs of secondary cosmic rays with the

${ }_{65}$ source located at $0.5-2 \mathrm{~km}$ within the region between the main negative charge and the

${ }_{66}$ Lower Positive Charge Layer (LPCL), both for those observed at sea level and for those

${ }_{67}$ observed at mountain tops [Chilingarian, 2014].

${ }_{68} \quad$ On the other hand, Montanyà et al. [2014] reported the increment of high-energy counts

${ }_{69}$ clearly associated with precipitation (30 dBZ radar reflectivity) rather than storm electri-

70 fication. This experiment was carried out on a mountain peak at $2500 \mathrm{~m}$. The negative

${ }_{71}$ charge region was located near $\sim 5.6 \mathrm{~km}$, which is $\sim 3 \mathrm{~km}$ above the detectors. Count rate

${ }_{72}$ increments were attributed to Radon $\left({ }^{222} \mathrm{Rn}\right.$ and $\left.{ }^{220} \mathrm{Rn}\right)$, i.e., radon-ion daughters, as also

73 concluded by some other previous publications [Suszcynsky et al., 1996; Mallick et al.,

${ }_{74}$ 2012]. Radon-ion daughters are products of the radiative decay chain of Uranium-238

${ }^{75}\left({ }^{238} \mathrm{U}\right)$ and Thoron-232 $\left({ }^{232} \mathrm{Th}\right)$. The existence of the increase of high energy radiation

76 due to the radiative decay of radon-ion daughters during rain is a phenomenon that has

77 been studied in great detail [Fujinami et al., 1985; Paatero and Hatakka, 1994; Vecchi

${ }_{78}$ et al., 2004; Takeyasu et al., 2006; Nayak et al., 2016].

79 The main aim of this paper is to find out if the high-energy background increments so reported are long TGEs related to the storm electrification or to other factors like radiative ${ }_{81}$ decay of radon-ion daughters during precipitation. In order to achieve this objective we ${ }_{82}$ have analysed six episodes of high-energy radiation enhancements associated with storms

8s divided in two groups, three days in winter and three days in summer, with eight winter ${ }_{84}$ storms and five summer storms identified. We present in section 2 the instruments used, 
${ }_{85}$ the methodology and the data analysed. Results are presented in section 3 and discussed

${ }_{86}$ in section 4. Finally, the main conclusions are summarized in section 5.

\section{Instruments and data}

Observations presented in this study were conducted in the Ebro delta region which

${ }_{88}$ is part of the so-called Ebro Valley Laboratory in the northeast of Spain. A specific

s9 instrument for the measurement of high-energy radiation was installed in the region in

90 the specific location known as MonNatura, and has been in continuous operation from October 2013 to February 2015 (figure 1). This instrument consists of two $\varnothing 76 \mathrm{~mm}$

92 $\mathrm{NaI}(\mathrm{Tl}) /$ photomultiplier tube scintillator detectors that are located within an aluminium

${ }_{93}$ box of $5 \mathrm{~mm}$ thickness wall to guarantee a good insulation of electromagnetic interference

94 such as the intense electromagnetic fields produced by lightning. Both scintillators point upward behind two apertures covered by an aluminium foil of $1 \mathrm{~mm}$. The first one

${ }_{96}$ is used to record transient high-energy radiation bursts associated with close lightning

${ }_{97}$ strikes. The second one is connected to the DP5G multichannel analyser of AMPTEK.

${ }_{98}$ This multichannel analyser is configured in the 1024 channels mode and is used to record cumulated counts of the high-energy background radiation in periods of 1 minute in the energy range $0.1-2 \mathrm{MeV}$. In this paper only the analysis of the background radiation detected by the second scintillator is carried out. 
${ }_{130}$ the table 1). We have also used reanalysis data of ERA-Interim [Dee et al., 2011] together 


\section{Analysis of data}

\subsection{Winter Storms}


${ }_{174}$ 4.a,b). However, in this case there is no lightning activity close enough to MonNatura to 175 allow the inference of charge regions altitudes (figure 3.c). For this case the spectrum of 176 two periods of one hour corresponding to rain and no-rain situations in the figure 9 it is ${ }_{177}$ also presented. The peaks 1 to 5 and 7 that exist only in the rainy period corresponds to ${ }_{178}$ radon-ion daughter decay energies, while the peak 6 that exists in both cases corresponds to potassium, as can be seen in the table 2 . As previously mentioned, only one spectrum ${ }_{180}$ is presented because same peaks appear in the six episodes.

The last winter case, the 18 January 2014 episode, it has two identified storms (figure ) ${ }_{182}$ between 0600 and 0800 UTC in the morning. For the first storm there is a good agreement ${ }_{183}$ between radiation and reflectivity increases but there was not convection (radar reflectivity below $35 \mathrm{dBZ}$, figures 4.a,b) and T10R $>0$, T90R $>0$ and T90R $>$ T10R (table 1). Only

185 the second one can be considered a thunderstorm, but no charge regions altitudes have ${ }_{186}$ been found (figures 4.c). For the second thunderstorm it can be observed in the figures 5.a

\subsection{Summer Storms}




\subsection{Single transient event}

\section{Discussion}


${ }_{240}$ be attached to water droplets when they precipitate. These radon-ion daughters can

fall down above detectors during rain and then decay by $\alpha$ or $\beta$ emissions. Radon-ion daughters are usually excited after the decay, what results in a $\gamma$ emission that can be detected by high-energy detectors (see Bhandari [1963] for an extended explanation of radon-ion daughters). The $\mathrm{NaI}(\mathrm{Tl})$ scicntillator used to detect high-energy background radiation operates in the energy range from 0.1 to $2 \mathrm{MeV}$. Radon-ion daughters emit energies in the range from $0.1 \mathrm{MeV}$ to $3 \mathrm{MeV}$ [Yamazaki et al., 2002], which means that it is not easy to discern if radiation increments reported are due to radon-ion daughters or other factors. However, the spectra of figure 9 show that radon increment is mainly due to radon-ion daughters listed in table 2 . We can see that 5 of them are descendants s50 of ${ }^{222} \mathrm{Rn}$ while only one is a descendant of ${ }^{220} \mathrm{Rn}$. That makes sense because although both radon isotopes have similar concentration in the atmosphere, half-life of ${ }^{222} \mathrm{Rn}$ is about 4 days while half-live of ${ }^{220} \mathrm{Rn}$ is about 56 seconds (from Toxicological profile for radon, 1990, by the Agency for Toxic Substances and Disease Registry of the U.S. Public ${ }^{254}$ Health Service in collaboration with the U.S. Environmental Protection Agency). These spectra are comparable to the ones obtained by Takeyasu et al. [2006] and Nayak et al. [2016] who found energetic peaks associated to the ${ }^{214} \mathrm{~Pb}$ and ${ }^{214} \mathrm{Bi}$ radon-ion daughters during rainy periods. As commented before, the spectra of the 13 storms is quite similar (this is why only one case is presented), however it is important to comment that the radon-ion daughters peaks are higher during winter cases. This result agrees with Vecchi et al. [2004], who found that radon concentrations have the highest values during winter season and the lowest values during summer season. 
${ }_{308}$ at the tower, runaway electrons accelerated toward the ground in the high electric field 
${ }_{331}$ of the second storm of 18 January 2014 (figure 5.c), but there was not any associated

\section{Conclusions}


353 of LPCL additionally with the location of the instrument at the top of mountain at 2537

${ }_{354} \mathrm{~m}$ asl. Despite these results, the use of a detector in an energy from $0.1 \mathrm{MeV}$ to $2 \mathrm{Mev}$

355 does not allow to completely exclude the possibility that part of the high-energy radia-

356 tion measured should be related storm electrification. In a future experiment we will use,

${ }_{357}$ together with the current detector, another with a broader energy range.

Acknowledgments. This study was supported by research grants from the Spanish

\section{References}


Carlson, B. E., Lehtinen, N. G., Inan, U. S., oct 2010. Terrestrial gamma ray flash production by active lightning leader channels. Journal of Geophysical Research 115 (A10), A10324.

Celestin, S., Pasko, V. P., mar 2011. Energy and fluxes of thermal runaway electrons produced by exponential growth of streamers during the stepping of lightning leaders and in transient luminous events. Journal of Geophysical Research 116 (A3), A03315.

Chilingarian, A., jan 2014. Thunderstorm ground enhancementsModel and relation to lightning flashes. Journal of Atmospheric and Solar-Terrestrial Physics 107, 68-76.

Chilingarian, A., Bostanjyan, N., Vanyan, L., apr 2012. Neutron bursts associated with thunderstorms. Physical Review D 85 (8), 085017.

Chilingarian, A., Daryan, A., Arakelyan, K., Hovhannisyan, A., Mailyan, B., Melkumyan, L., Hovsepyan, G., Chilingaryan, S., Reymers, A., Vanyan, L., aug 2010. Ground-based observations of thunderstorm-correlated fluxes of high-energy electrons, gamma rays, and neutrons. Physical Review D 82 (4), 043009.

Chilingarian, A., Hovsepyan, G., Hovhannisyan, A., mar 2011. Particle bursts from thunderclouds: Natural particle accelerators above our heads. Physical Review D 83 (6), 062001.

Chilingarian, A., Mkrtchyan, H., oct 2012. Role of the Lower Positive Charge Region (LPCR) in initiation of the Thunderstorm Ground Enhancements (TGEs). Physical Review D 86 (7), 072003.

Dee, D. P., Uppala, S. M., Simmons, A. J., Berrisford, P., Poli, P., Kobayashi, S., Andrae, U., Balmaseda, M. A., Balsamo, G., Bauer, P., Bechtold, P., Beljaars, A. C. M., van de Berg, L., Bidlot, J., Bormann, N., Delsol, C., Dragani, R., Fuentes, M., Geer, A. J., 
Haimberger, L., Healy, S. B., Hersbach, H., Hólm, E. V., Isaksen, L., Kållberg, P.,

Köhler, M., Matricardi, M., McNally, A. P., Monge-Sanz, B. M., Morcrette, J.-J., Park, B.-K., Peubey, C., de Rosnay, P., Tavolato, C., Thépaut, J.-N., Vitart, F., apr 2011. The ERA-Interim reanalysis: configuration and performance of the data assimilation system. Quarterly Journal of the Royal Meteorological Society 137 (656), 553-597.

Dwyer, J. R., 2005a. The initiation of lightning by runaway air breakdown. Geophysical Research Letters 32 (20), L20808.

Dwyer, J. R., 2005b. X-ray bursts associated with leader steps in cloud-to-ground lightning. Geophysical Research Letters 32 (1), L01803.

Dwyer, J. R., may 2008. Source mechanisms of terrestrial gamma-ray flashes. Journal of Geophysical Research 113 (D10), D10103.

Dwyer, J. R., mar 2010. Diffusion of relativistic runaway electrons and implications for lightning initiation. Journal of Geophysical Research 115, A00E14.

Dwyer, J. R., Rassoul, H. K., Al-Dayeh, M., Caraway, L., Wright, B., Chrest, A., Uman, M. A., Rakov, V. A., Rambo, K. J., Jordan, D. M., Jerauld, J., Smyth, C., mar 2004. Measurements of x-ray emission from rocket-triggered lightning. Geophysical Research Letters 31 (5), n/a-n/a.

Dwyer, J. R., Saleh, Z., Rassoul, H. K., Concha, D., Rahman, M., Cooray, V., Jerauld, J., Uman, M. A., Rakov, V. A., dec 2008. A study of X-ray emission from laboratory sparks in air at atmospheric pressure. Journal of Geophysical Research 113 (D23), D23207.

Dwyer, J. R., Smith, D. M., 2005. A comparison between Monte Carlo simulations of runaway breakdown and terrestrial gamma-ray flash observations. Geophysical Research Letters 32 (22), L22804. 
Dwyer, J. R., Smith, D. M., Cummer, S. A., jun 2012. High-Energy Atmospheric Physics: Terrestrial Gamma-Ray Flashes and Related Phenomena. Space Science Reviews 173 (14), 133-196.

Dwyer, J. R., Uman, M. A., Rassoul, H. K., Al-Dayeh, M., Caraway, L., Jerauld, J., Rakov, V. A., Jordan, D. M., Rambo, K. J., Corbin, V., Wright, B., jan 2003. Energetic radiation produced during rocket-triggered lightning. Science (New York, N.Y.) 299 (5607), 694-7.

Eack, K. B., Beasley, W. H., Rust, W. D., Marshall, T. C., Stolzenburg, M., dec 1996. Initial results from simultaneous observation of X-rays and electric fields in a thunderstorm. Journal of Geophysical Research 101 (D23), 29637.

Fishman, G. J., Bhat, P. N., Mallozzi, R., Horack, J. M., Koshut, T., Kouveliotou, C., Pendleton, G. N., Meegan, C. A., Wilson, R. B., Paciesas, W. S., Goodman, S. J., Christian, H. J., may 1994. Discovery of intense gamma-ray flashes of atmospheric origin. Science (New York, N.Y.) 264 (5163), 1313-6.

Fujinami, N., Esaka, S., Minato, S., jul 1985. Influence of the precipitation rate on the seasonal variation in the specific radioactivity of short-lived222Rn daughters in precipitation. Journal of Radioanalytical and Nuclear Chemistry Letters 95 (2), 111-117.

Gjesteland, T., Østgaard, N., Connell, P. H., Stadsnes, J., Fishman, G. J., may 2010. Effects of dead time losses on terrestrial gamma ray flash measurements with the Burst and Transient Source Experiment. Journal of Geophysical Research 115, A00E21.

Gurevich, A., nov 1961. ON THE THEORY OF RUNAWAY ELECTRONS. Soviet Phys. JETP 12(5), 904-912. 
${ }_{442}$ Gurevich, A., Milikh, G., Roussel-Dupre, R., jun 1992. Runaway electron mechanism of air breakdown and preconditioning during a thunderstorm. Physics Letters A 165 (5-6), $463-468$.

Gurevich, A. V., Antonova, V. P., Chubenko, A. P., Karashtin, A. N., Mitko, G. G., Ptitsyn, M. O., Ryabov, V. A., Shepetov, A. L., Shlyugaev, Y. V., Vildanova, L. I., Zybin, K. P., feb 2013. Cosmic rays and thunderstorms at the Tien-Shan mountain station. Journal of Physics: Conference Series 409 (1), 012234.

Hazelton, B. J., Grefenstette, B. W., Smith, D. M., Dwyer, J. R., Shao, X.-M., Cummer, S. A., Chronis, T., Lay, E. H., Holzworth, R. H., jan 2009. Spectral dependence of terrestrial gamma-ray flashes on source distance. Geophysical Research Letters 36 (1), L01108.

Howard, J., Uman, M. A., Dwyer, J. R., Hill, D., Biagi, C., Saleh, Z., Jerauld, J., Rassoul, H. K., jul 2008. Co-location of lightning leader x-ray and electric field change sources. Geophysical Research Letters 35 (13), L13817.

Kochkin, P. O., Nguyen, C. V., van Deursen, A. P. J., Ebert, U., oct 2012. Experimental study of hard x-rays emitted from metre-scale positive discharges in air. Journal of Physics D: Applied Physics 45 (42), 425202.

Krehbiel, P. R., 1986. The electrical structure of thunderstorms, The Earth's Electrical Enviroment, Studies in Geophysics. National Academy Press, Washington D.C.

Krehbiel, P. R., Riousset, J. A., Pasko, V. P., Thomas, R. J., Rison, W., Stanley, M. A., Edens, H. E., apr 2008. Upward electrical discharges from thunderstorms. Nature Geoscience 1 (4), 233-237. 
${ }_{464}$ Lu, G., Blakeslee, R. J., Li, J., Smith, D. M., Shao, X.-M., McCaul, E. W., Buechler, D. E.,

Christian, H. J., Hall, J. M., Cummer, S. A., jun 2010. Lightning mapping observation of a terrestrial gamma-ray flash. Geophysical Research Letters 37 (11), n/a-n/a.

Mallick, S., Rakov, V. A., Dwyer, J. R., aug 2012. A study of X-ray emissions from thunderstorms with emphasis on subsequent strokes in natural lightning. Journal of Geophysical Research 117 (D16), D16107.

March, V., Arrayás, M., Trueba, J. L., Montanyà, J., Romero, D., Solà, G., Aranguren, D., may 2009. Features of electrical discharges in air triggered by laser. Journal of Electrostatics 67 (2-3), 301-306.

March, V., Montanyà, J., oct 2010. Influence of the voltage-time derivative in X-ray emission from laboratory sparks. Geophysical Research Letters 37 (19), n/a-n/a.

Montanyà, J., Fabró, F., van der Velde, O., Romero, D., Solà, G., Hermoso, J. R., Soula, S., Williams, E. R., Pineda, N., feb 2014. Registration of X-rays at 2500m altitude in association with lightning flashes and thunderstorms. Journal of Geophysical Research: Atmospheres 119 (3), 1492-1503.

Moore, C. B., Eack, K. B., Aulich, G. D., Rison, W., jun 2001. Energetic radiation associated with lightning stepped-leaders. Geophysical Research Letters 28 (11), 21412144.

Nayak, P., Gupta, S., Jain, A., Mazumdar, I., Raha, S., jan 2016. Study of terrestrial $\gamma$-ray background in presence of variable radioactivity from rain water. Astroparticle Physics 72, 55-60.

Nguyen, C. V., van Deursen, A. P. J., Ebert, U., dec 2008. Multiple x-ray bursts from long discharges in air. Journal of Physics D: Applied Physics 41 (23), 234012. 
Østgaard, N., Gjesteland, T., Stadsnes, J., Connell, P. H., Carlson, B., feb 2008. Production altitude and time delays of the terrestrial gamma flashes: Revisiting the Burst and Transient Source Experiment spectra. Journal of Geophysical Research 113 (A2), A02307.

Paatero, J., Hatakka, J., 1994. No TitleWet deposition efficiency of short-lived radon-222 progeny in central Finland. BOREAL ENVIRONMENT RESEARCH 4, 285-293.

Parks, G. K., Mauk, B. H., Spiger, R., Chin, J., nov 1981. X-ray enhancements detected during thunderstorm and lightning activities. Geophysical Research Letters 8 (11), $1176-1179$

Pineda, N., Rigo, T., Montanyà, J., van der Velde, O. A., sep 2016. Charge structure analysis of a severe hailstorm with predominantly positive cloud-to-ground lightning. Atmospheric Research 178-179, 31-44.

Saleh, Z., Dwyer, J., Howard, J., Uman, M., Bakhtiari, M., Concha, D., Stapleton, M., Hill, D., Biagi, C., Rassoul, H., sep 2009. Properties of the X-ray emission from rocket-triggered lightning as measured by the Thunderstorm Energetic Radiation Array (TERA). Journal of Geophysical Research 114 (D17), D17210.

Schaal, M. M., Dwyer, J. R., Rassoul, H. K., Hill, J. D., Jordan, D. M., Uman, M. A., oct 2013. The angular distribution of energetic electron and X-ray emissions from triggered lightning leaders. Journal of Geophysical Research: Atmospheres 118 (20), 11,71211,726

Shao, T., Zhang, C., Niu, Z., Yan, P., Tarasenko, V. F., Baksht, E. K., Burahenko, A. G., Shut'ko, Y. V., jan 2011. Diffuse discharge, runaway electron, and x-ray in atmospheric pressure air in an inhomogeneous electrical field in repetitive pulsed modes. Applied 

A00E30. 23505.

Physics Letters 98 (2), 021503.

Shao, X.-M., Hamlin, T., Smith, D. M., jun 2010. A closer examination of terrestrial gamma-ray flash-related lightning processes. Journal of Geophysical Research 115,

Suszcynsky, D. M., Roussel-Dupre, R., Shaw, G., oct 1996. Ground-based search for X rays generated by thunderstorms and lightning. Journal of Geophysical Research 101 (D18),

Takeyasu, M., Iida, T., Tsujimoto, T., Yamasaki, K., Ogawa, Y., jan 2006. Concentrations and their ratio of (222)Rn decay products in rainwater measured by gamma-ray spectrometry using a low-background Ge detector. Journal of environmental radioactivity $88(1), 74-89$.

Torii, T., Sugita, T., Kamogawa, M., Watanabe, Y., Kusunoki, K., dec 2011. Migrating source of energetic radiation generated by thunderstorm activity. Geophysical Research Letters $38(24), \mathrm{n} / \mathrm{a}-\mathrm{n} / \mathrm{a}$.

Torii, T., Sugita, T., Muraki, Y., 2008. Observation of the gradual increases and bursts of energetic radiation associated with the activity of the winter thunderstorm.

Torii, T., Sugita, T., Tanabe, S., Kimura, Y., Kamogawa, M., Yajima, K., Yasuda, H., jul 2009. Gradual increase of energetic radiation associated with thunderstorm activity at the top of Mt. Fuji. Geophysical Research Letters 36 (13), L13804.

Tsuchiya, H., Enoto, T., Torii, T., Nakazawa, K., Yuasa, T., Torii, S., Fukuyama, T., Yamaguchi, T., Kato, H., Okano, M., Takita, M., Makishima, K., jun 2009. Observation of an Energetic Radiation Burst from Mountain-Top Thunderclouds. Physical Review Letters 102 (25), 255003. 
Tsuchiya, H., Enoto, T., Yamada, S., Yuasa, T., Kawaharada, M., Kitaguchi, T., Kokubun, M., Kato, H., Okano, M., Nakamura, S., Makishima, K., oct 2007. Detection of High-Energy Gamma Rays from Winter Thunderclouds. Physical Review Letters $99(16), 165002$.

Tsuchiya, H., Enoto, T., Yamada, S., Yuasa, T., Nakazawa, K., Kitaguchi, T., Kawaharada, M., Kokubun, M., Kato, H., Okano, M., Makishima, K., may 2011. Longduration $\gamma$ ray emissions from 2007 and 2008 winter thunderstorms. Journal of Geophysical Research 116 (D9), D09113.

van der Velde, O. A., Montanyà, J., dec 2013. Asymmetries in bidirectional leader development of lightning flashes. Journal of Geophysical Research: Atmospheres 118 (24), $13,504-13,519$

Vecchi, R., Marcazzan, G., Valli, G., Ceriani, M., Antoniazzi, C., sep 2004. The role of atmospheric dispersion in the seasonal variation of PM1 and PM2.5 concentration and composition in the urban area of Milan (Italy). Atmospheric Environment 38 (27), $4437-4446$

Williams, E., Boldi, R., Bór, J., Sátori, G., Price, C., Greenberg, E., Takahashi, Y., Yamamoto, K., Matsudo, Y., Hobara, Y., Hayakawa, M., Chronis, T., Anagnostou, E., Smith, D. M., Lopez, L., 2006. Lightning flashes conducive to the production and escape of gamma radiation to space. Journal of Geophysical Research 111 (D16), D16209.

Wilson, C., oct 1925. The Acceleration of $\beta$-particles in Strong Electric Fields such as those of Thunderclouds. Mathematical Proceedings of the Cambridge Philosophical Society $22(04), 534-538$ 


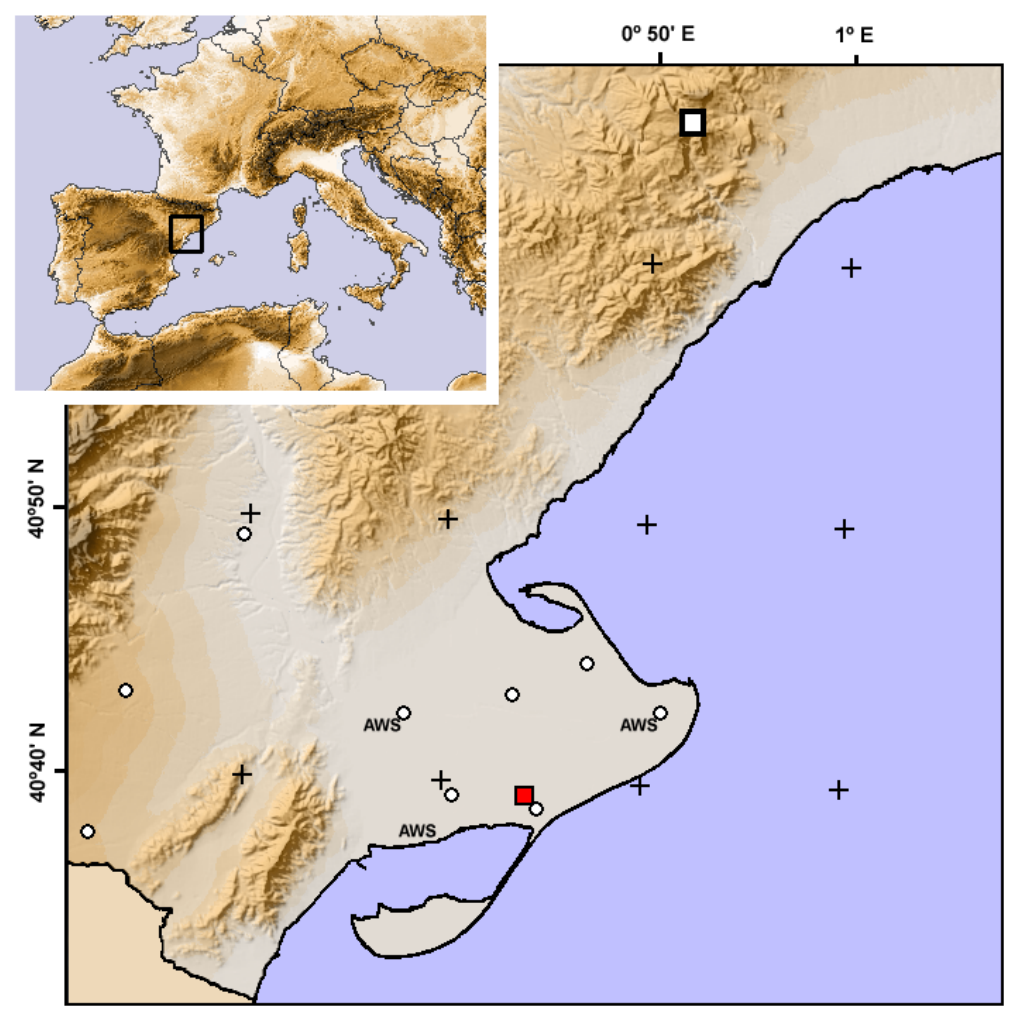

Figure 1. Location of the $\mathrm{NaI}(\mathrm{TL})$ scitillator (red aquare), automathic weather stations (AWS), LMA antennas (white circles) and radar (white square) in the Ebro delta in the north-east of Spain

Yamazaki, K., Tonouchi, S., Hashimoto, T., 2002. Factors associated with the variations

${ }_{556}$ in environmental gamma-ray spectra in Kashiwazaki Kariwa area. Journal of Radioan557 alytical and Nuclear Chemistry 252 (2), 359-366.

Yoshida, S., Morimoto, T., Ushio, T., Kawasaki, Z.-I., Torii, T., Wang, D., Takagi, N., Watanabe, T., may 2008. High energy photon and electron bursts associated with upward lightning strokes. Geophysical Research Letters 35 (10), L10804. 


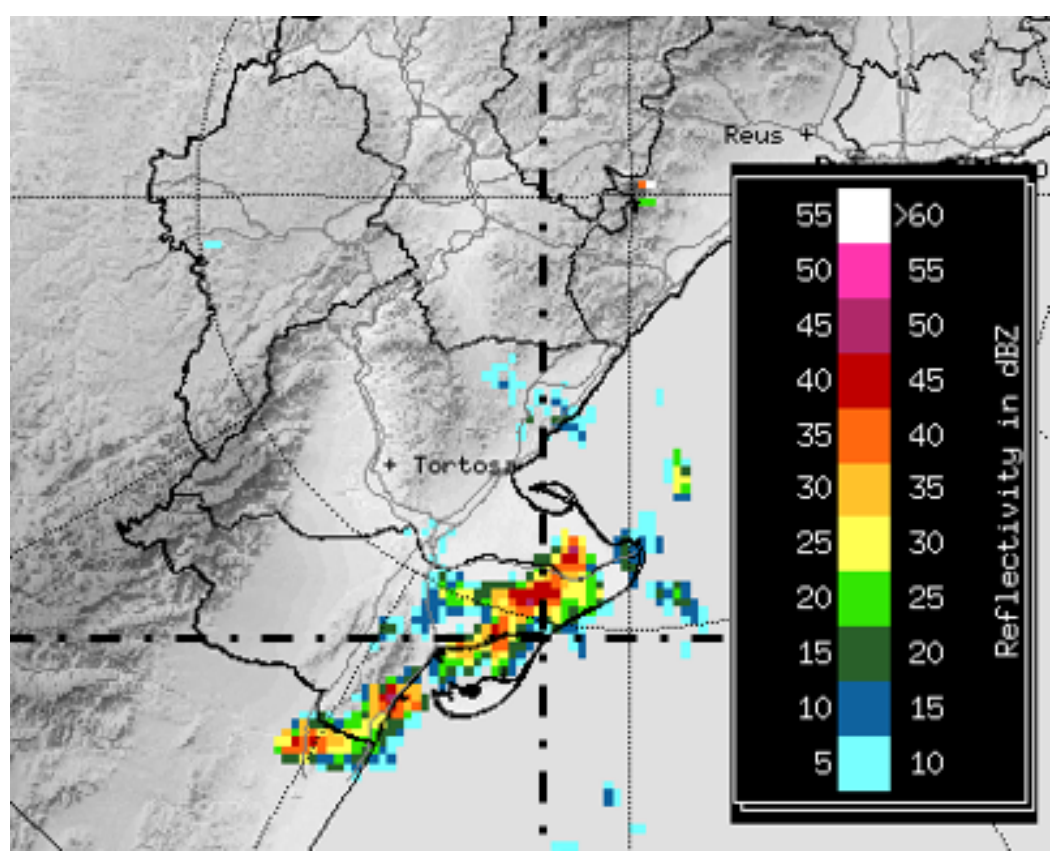

Figure 2. CAPPI at $1 \mathrm{~km}$ for the 29 August 2014 at 0518 UTC. MonNatura location is in the intersection of the dot-dash lines 

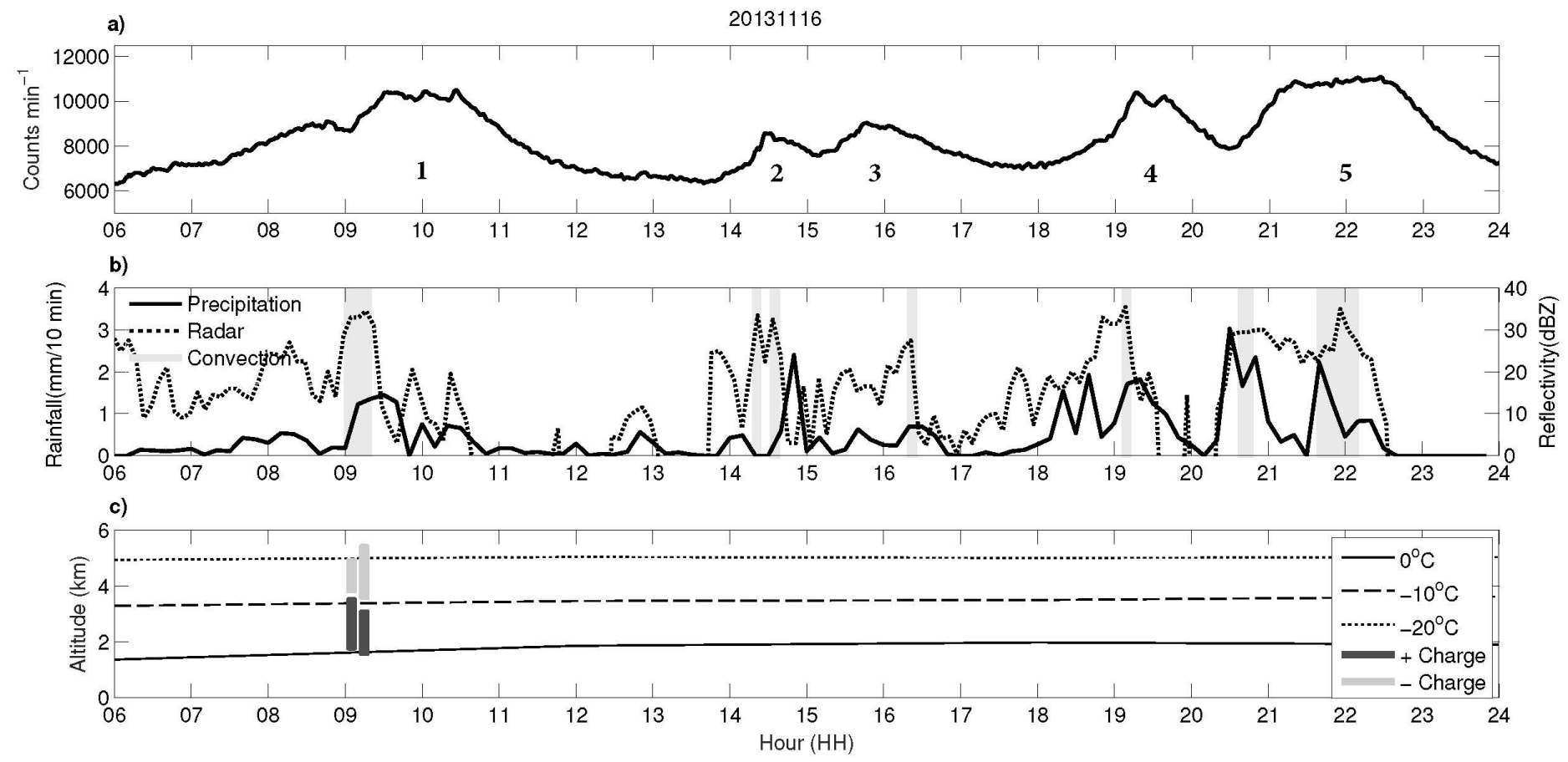

Figure 3. Time evolution for 30 November 2013 episode of (a) X ray counts, (b) maximum radar reflectivity and precipitation above the scintillator and (c) altitude of the $0^{\circ} \mathrm{C},-10^{\circ} \mathrm{C}$ and $-20^{\circ} \mathrm{C}$ isotherms charge regions altitudes inferred from LMA detections 

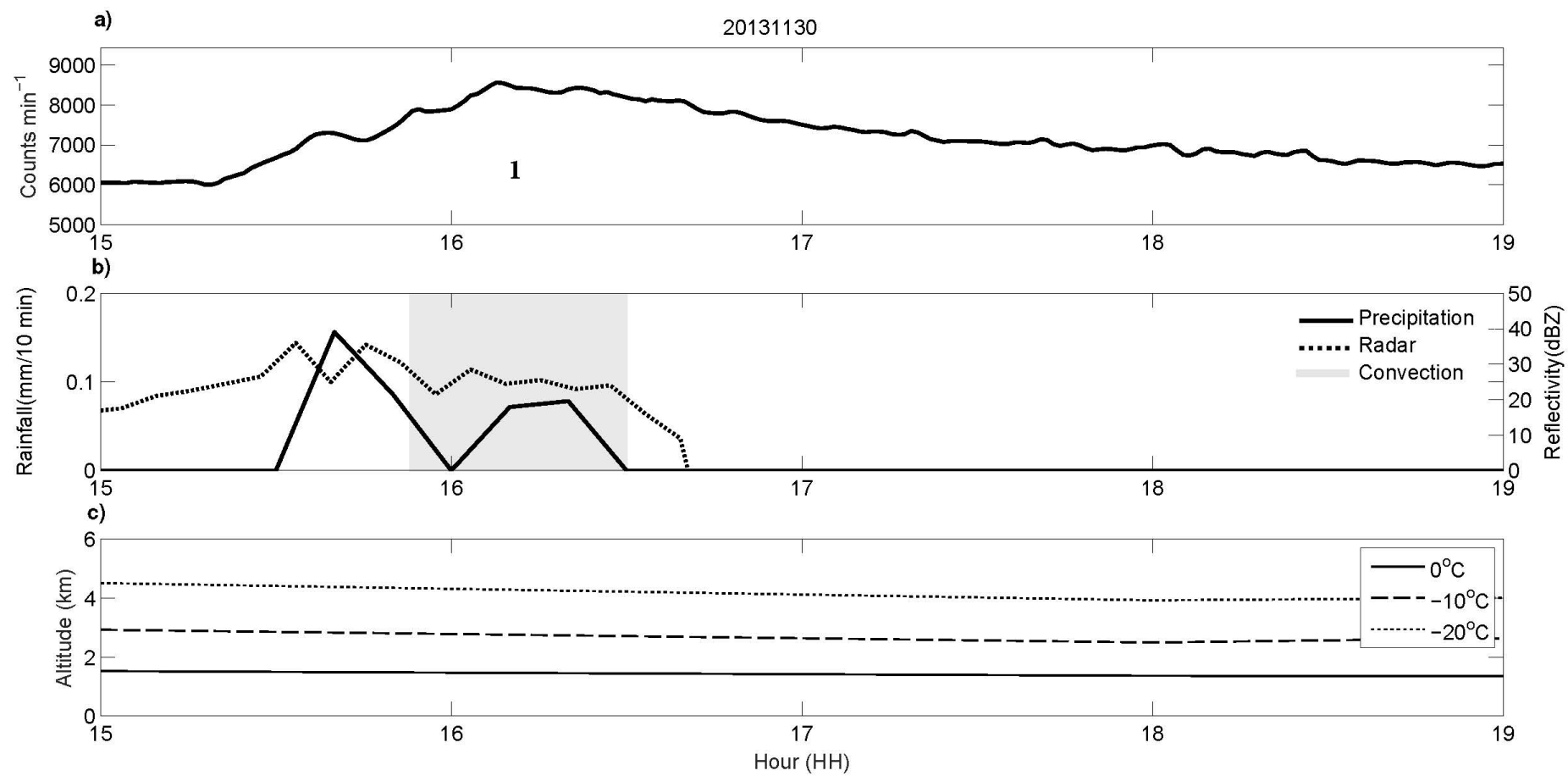

Figure 4. Time evolution for 30 November 2013 episode of (a) X ray counts, (b) maximum radar reflectivity and precipitation above the scintillator and (c) altitude of the $0^{\circ} \mathrm{C},-10^{\circ} \mathrm{C}$ and $-20^{\circ} \mathrm{C}$ isotherms charge regions altitudes inferred from LMA detections 

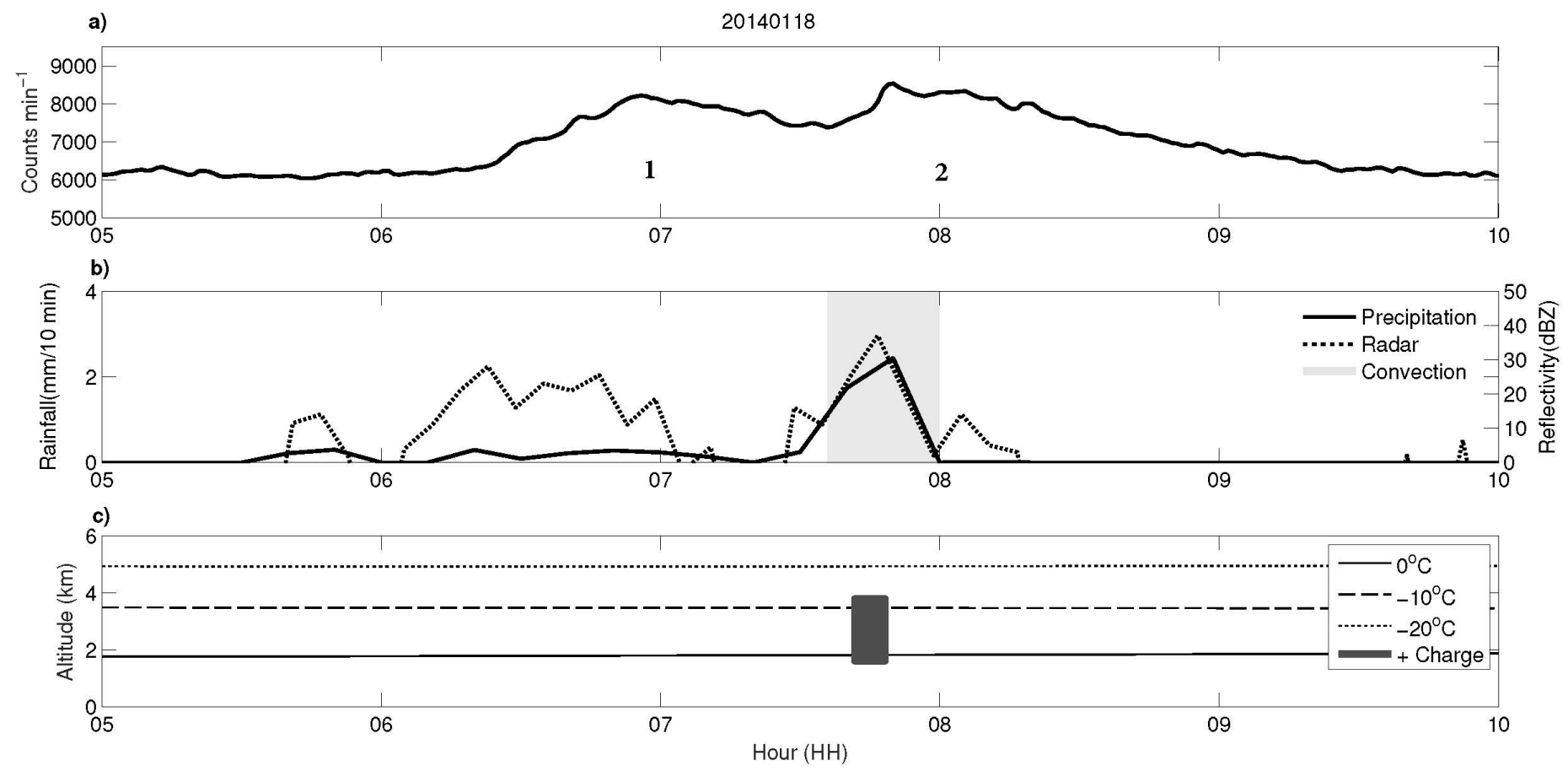

Figure 5. Time evolution for 18 January 2014 episode of (a) X ray counts, (b) maximum radar reflectivity and precipitation above the scintillator and (c) altitude of the $0^{\circ} \mathrm{C},-10^{\circ} \mathrm{C}$ and $-20^{\circ} \mathrm{C}$ isotherms charge regions altitudes inferred from LMA detections 

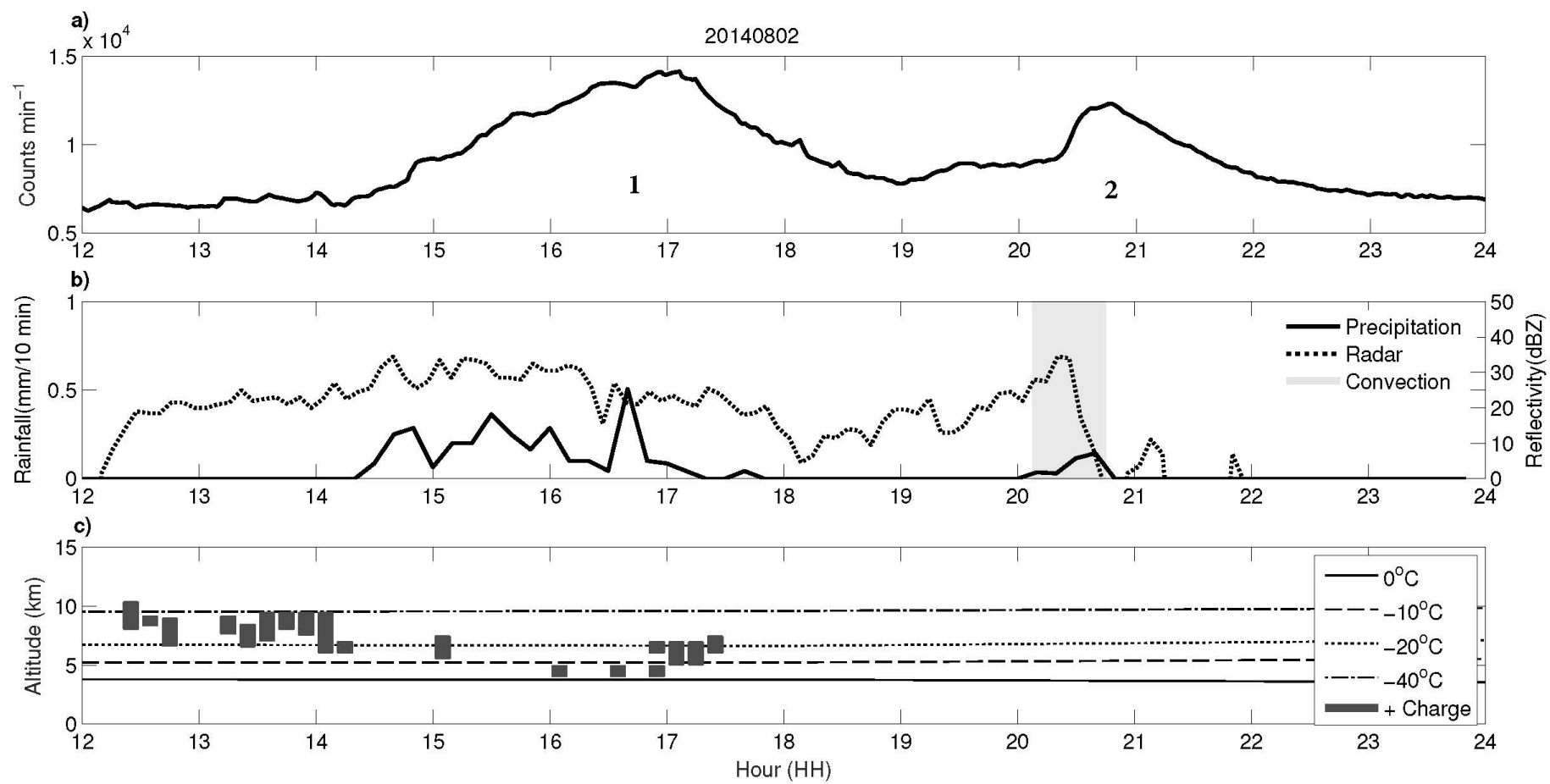

Figure 6. Time evolution for 2 August 2014 episode of (a) X ray counts, (b) maximum radar reflectivity and precipitation above the scintillator and (c) altitude of the $0^{\circ} \mathrm{C},-10^{\circ} \mathrm{C},-20^{\circ} \mathrm{C}$ and $-40^{\circ} \mathrm{C}$ isotherms charge regions altitudes inferred from LMA detections 

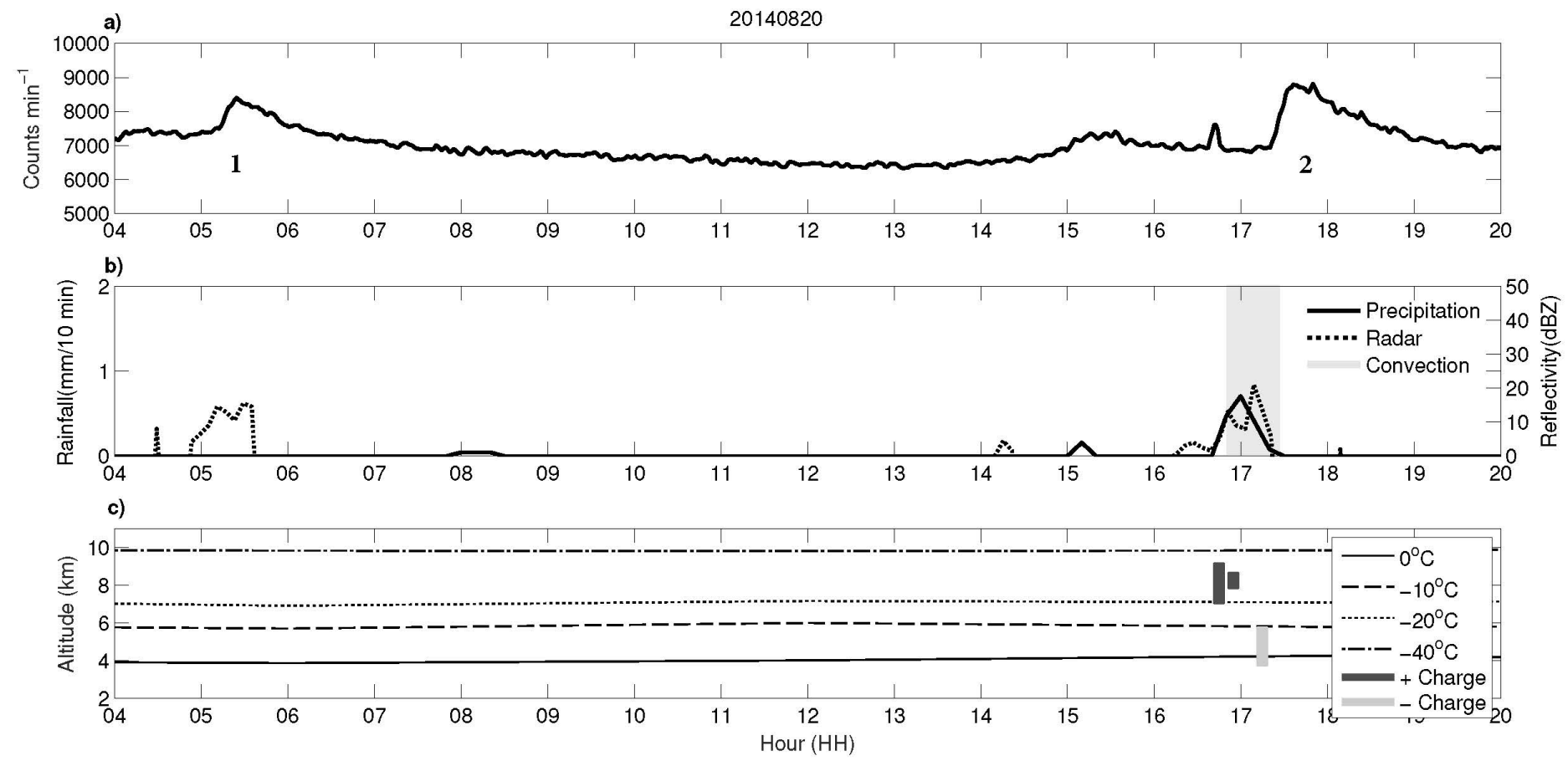

Figure 7. Time evolution for 20 August 2014 episode of (a) X ray counts, (b) maximum radar reflectivity and precipitation above the scintillator and (c) altitude of the $0^{\circ} \mathrm{C},-10^{\circ} \mathrm{C},-20^{\circ} \mathrm{C}$ and $-40^{\circ} \mathrm{C}$ isotherms charge regions altitudes inferred from LMA detections 

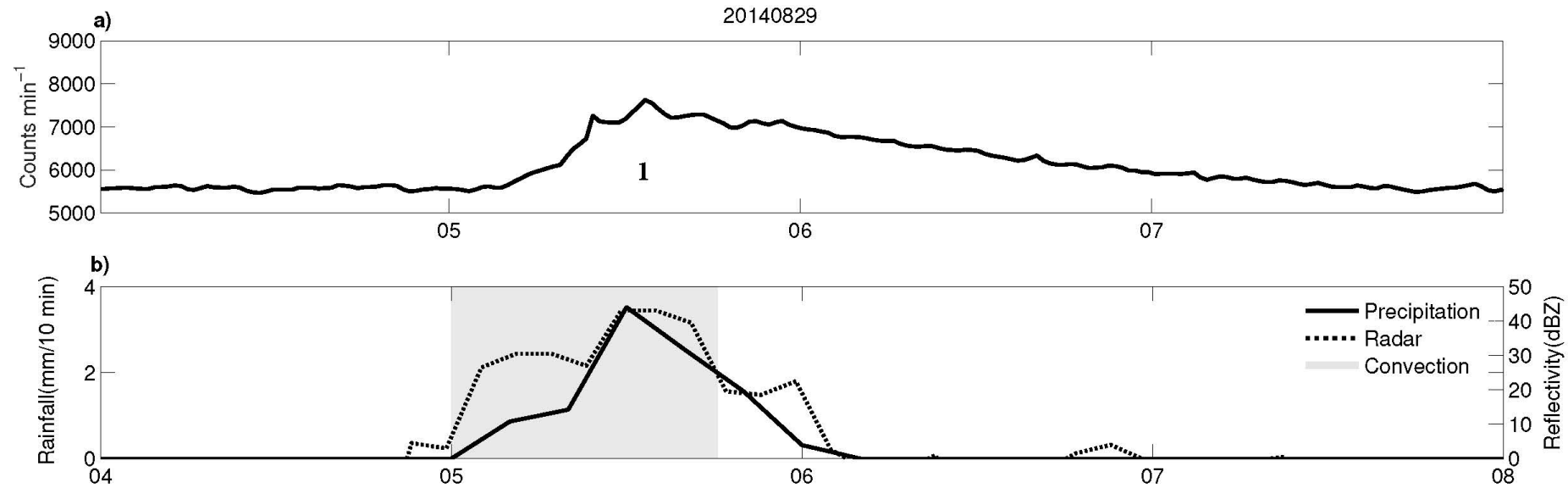

c)

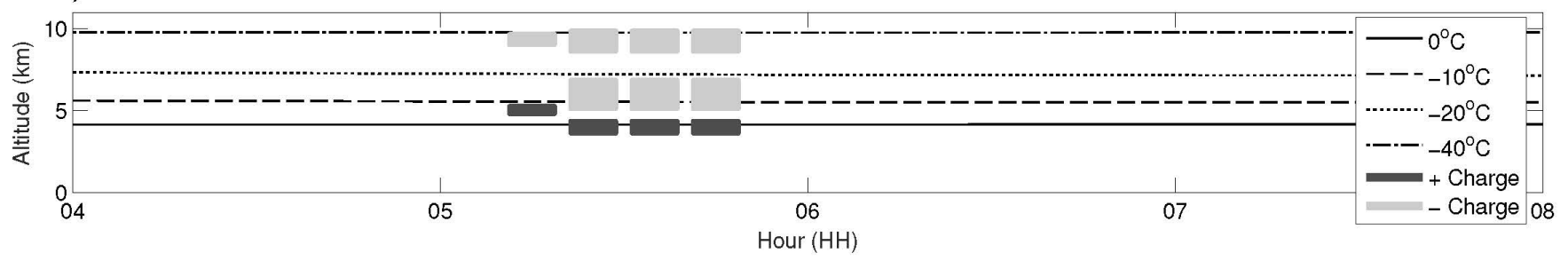

Figure 8. Time evolution for 29 August 2014 episode of (a) X ray counts, (b) maximum radar reflectivity and precipitation above the scintillator and (c) altitude of the $0^{\circ} \mathrm{C},-10^{\circ} \mathrm{C},-20^{\circ} \mathrm{C}$ and $-40^{\circ} \mathrm{C}$ isotherms charge regions altitudes inferred from LMA detections 


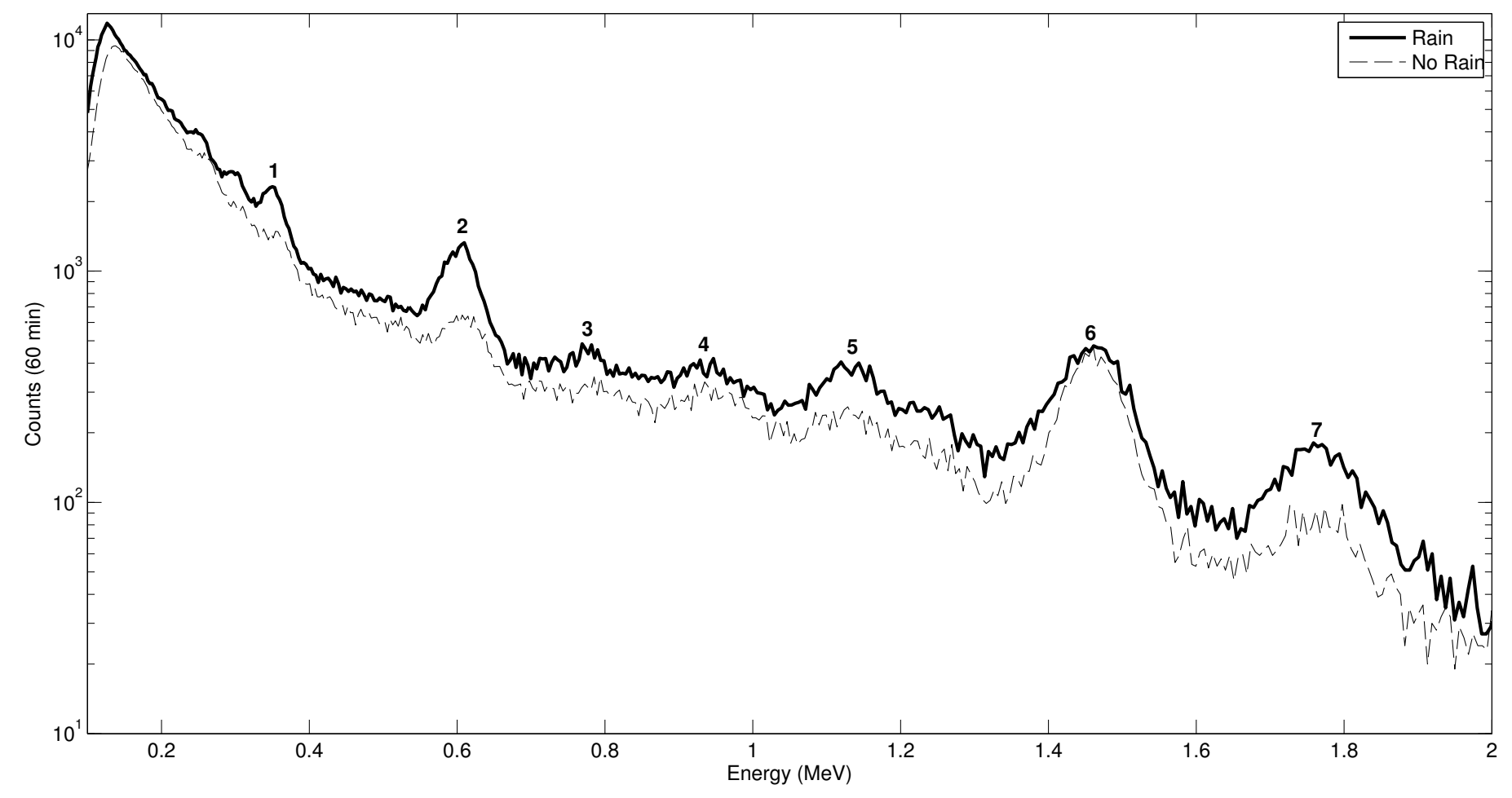

Figure 9. Energy spectra of 1 hour period with rain and 1 hour period without rain for the 30 November 2013 episode 

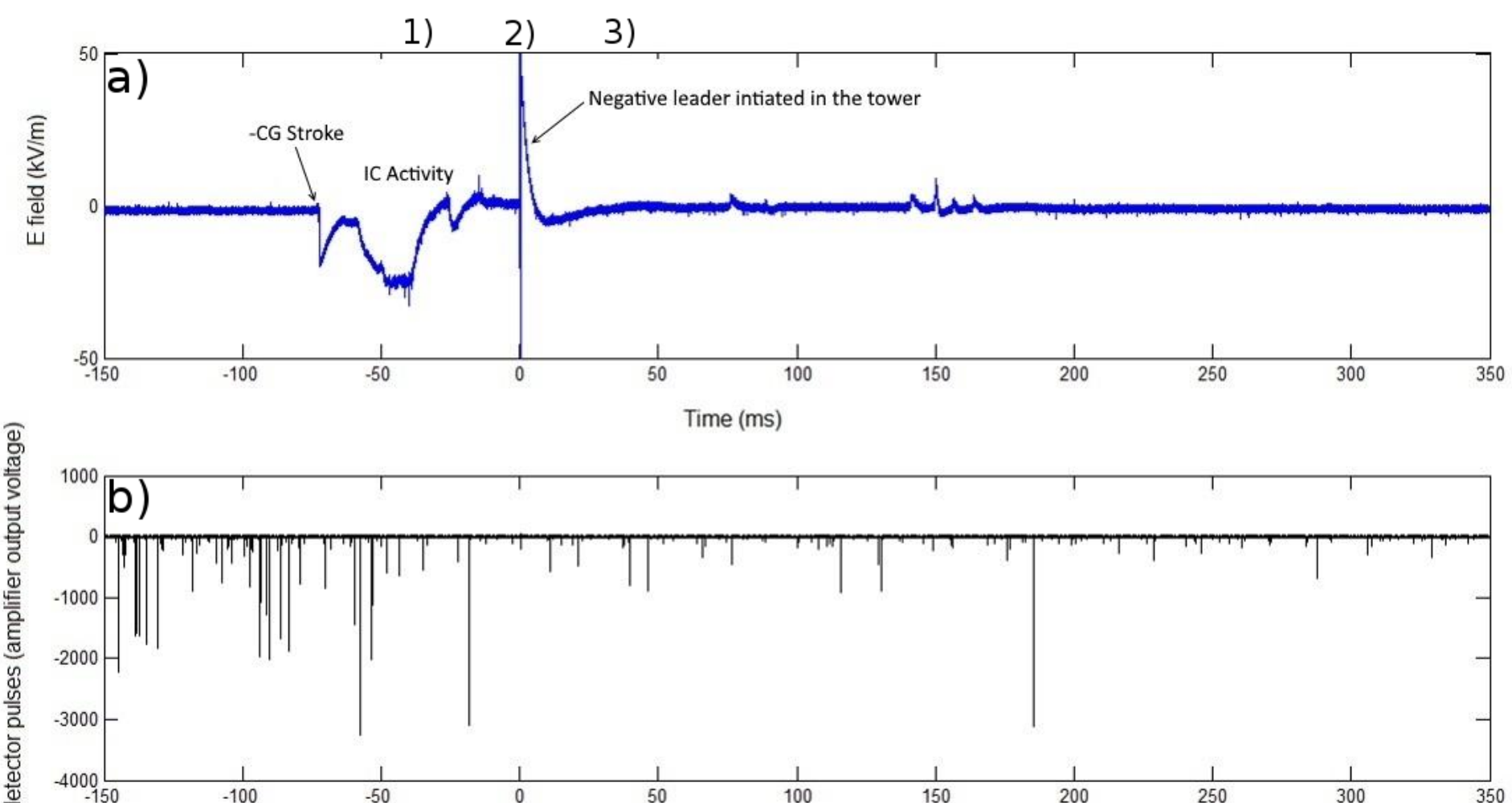

Time (ms)

Figure 10. Case of the 7 June 2011. (a) Electric field of a CG stroke $(-70 \mathrm{~ms})$ at $3.5 \mathrm{~km}$ from the tower and occurrence of an upward negative leader from the tower $(0 \mathrm{~ms})$. (b) X-rays pulses. Note the decrease of the intense pulse rate after the occurrence of the downward negative CG (-70 ms) and the induced upward negative leader (0 ms). The number 1, 2 and 3 corresponds to the moments of the figure 11 


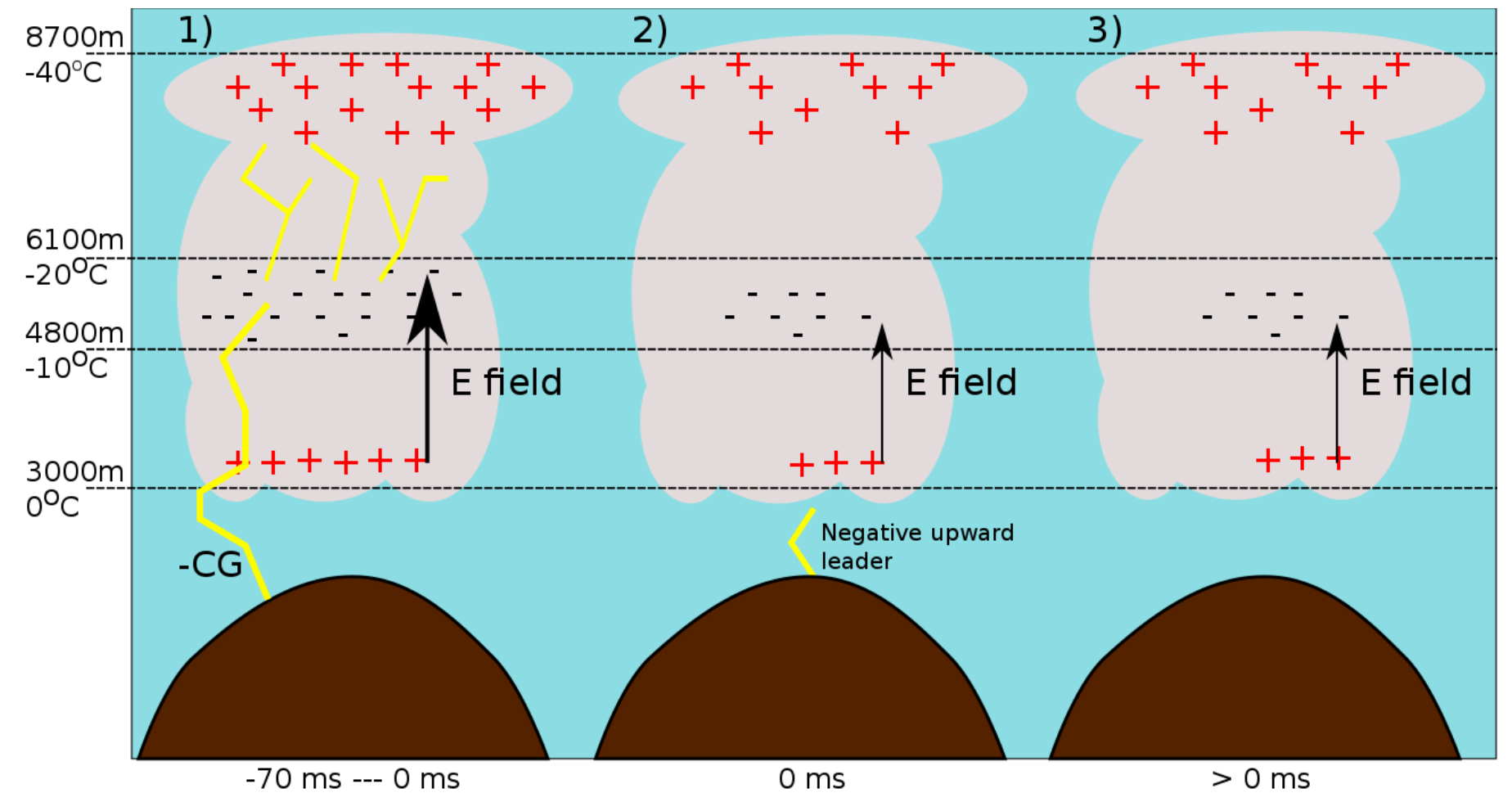

Figure 11. Case of 7 June 2011 occurring at the Eagle Nest tower at $2537 \mathrm{~m}$ asl. 1) Downward negative CG and and IC activity $(\mathrm{t}<0 \mathrm{~ms})$. The intensity of the electric field between the LPCL and main negative charge region has been decreasing progressively until the occurrence of the 2) upward negative leader $(\mathrm{t}=0 \mathrm{~ms})$. 3) The intensity of the electric field is not enough high to sustain the TGE ( $>0 \mathrm{~ms})$. 
Table 1. Time differences T10R, T90R, T10P and T90P of every one of the storms identified. The storm numbers in bold corresponds to thunderstorms.

\begin{tabular}{|c|c|c|c|c|c|c|}
\hline & Day & Storm & T10R (min) & T90R (min) & $\mathrm{T} 10 \mathrm{P}(\mathrm{min})$ & T90P (min) \\
\hline \multirow{8}{*}{ Winter } & 20131116 & 1 & 99 & 101 & -11 & 50 \\
\hline & & 2 & 16 & 19 & 10 & 1 \\
\hline & & 3 & 1.6 & 29 & -14 & 20 \\
\hline & & 4 & 47 & 40 & 15 & 30 \\
\hline & & 5 & 16 & 55 & 27 & 73 \\
\hline & 20131130 & 1 & 52 & 123 & 18 & 127 \\
\hline & 20140118 & 1 & 9 & 28 & - & - \\
\hline & & 2 & 17 & 71 & 9 & 88 \\
\hline \multirow{5}{*}{ Summer } & 20140802 & $\overline{11}$ & 134 & 441 & 40 & 85 \\
\hline & & 2 & 87 & 123 & 12 & 113 \\
\hline & 20140820 & 1 & -85 & 55 & - & - \\
\hline & & 2 & 34 & 93 & 38 & 102 \\
\hline & 20140829 & 1 & 6 & 54 & 8 & 58 \\
\hline
\end{tabular}

Table 2. Energies of the peaks identified in the spectrum of figure 9 of potassium and those corresponding to radon-ion daughters descendants of decay chains of uranium and thorium. (Adapted from Yamazaki et al. [2002])

\begin{tabular}{c|ccc} 
Peak & ${ }^{222} \mathrm{Rn}\left({ }^{238} \mathrm{U}\right.$ Series $)(\mathrm{MeV})$ & ${ }^{220} \mathrm{Rn}\left({ }^{235} \mathrm{Th}\right.$ Series $)(\mathrm{MeV})$ & ${ }^{40} \mathrm{~K}(\mathrm{MeV})$ \\
\hline 1 & ${ }^{214} \mathrm{~Pb}(0.352)$ & & \\
2 & ${ }^{214} \mathrm{Bi}(0.609)$ & & \\
3 & ${ }^{214} \mathrm{Bi}(0.768)$ & & \\
4 & & & \\
5 & ${ }^{214} \mathrm{Bi}(1.120)$ & \\
6 & & & \\
7 & ${ }^{214} \mathrm{Ki}(1.764)$ &
\end{tabular}

